\title{
THERMODYNAMIC MODELLING OF CEMENT CHEMISTRY AT HIGH TEMPERATURE
}

\author{
Mark Tyrer \\ Centre for Research in the Built and Natural Environment \\ Coventry University CV1 5FB United Kingdom
}

\begin{abstract}
The prediction of the likely future state of cementitious materials has been the focus of research for many decades and has expanded to match the availability of computational power and of codes and data. The field has traditionally been divided into two activities and even communities; high and low temperature methods. By tradition, each community has favoured its own models, codes and data but recent developments are leaving this boundary less distinct than in the past. To compound this, is the wider adoption of methods complementary to thermodynamics, which makes modelling high temperature cement chemistry an exciting area in which to conduct research. What follows, is a very personal view of the major advances in modelling cement chemistry at high temperatures, the needs and drivers to model development and an equally personal speculation about areas of fruitful research and development in the foreseeable future.
\end{abstract}

Keywords: Cementitious materials, Thermodynamic modelling, Modelling cement chemistry, High temperature.

\section{INTRODUCTION}

Why model the chemistry of cements? It is a reasonable question, especially if the questioner is unfamiliar with these materials. We are concerned with mankind's most abundantly produced material; of huge strategic importance to human development and wellbeing. For the provision of that basic human need of safe, affordable and secure accommodation, no other material approaches concrete as a satisfying our needs. In terms of global development, the use of this material continues to grow as the global population becomes increasingly more urban and our infrastructure of roads, bridges, airports and harbours expands to match our growing cities.

Our need to understand cement through modelling is fourfold:

- To predict the future evolution of cementitious materials long into the future

- To understand the mechanisms which control concrete durability

- To optimize the formulation of cements (especially for new formulations)

- To minimize the environmental impact of cement manufacture 
The last comment above, alludes to the enormous scale of cement manufacture. Globally, demand has increased steadily over many years, approximately doubling between 2004 and 2014 to around 4,200 million metric tonnes per anum. Although cement manufacture is one of the most clean and efficient manufacturing processes on earth, it operates on a larger scale than all other manufactured materials combined. Taking Portland cement as an example, the efficiency of Portland cement production has increased markedly over the last 30 years, such that a modern cement kiln operates at only a little above the thermodynamic (theoretical) minimum of $\sim 2.8 \mathrm{GJ} /$ tonne of cement. Globally, the energy efficiency has continued to increase as dry-process kilns (including staged preheaters and precalciners) replace wetprocess kilns and as more efficient grinding equipment is employed. Overall, the energy 'intensity' of clinker production was estimated at $3.4 \mathrm{GJ} / \mathrm{t}$ on average in 2017. This is a remarkable manufacturing success and greatly exceeds that of steel, glass, pharmaceuticals, or plastics and generates almost no solid or liquid waste. It does however, liberate carbon dioxide both from fossil fuel use and decarbonating limestone in the kiln. Cement is made of a vast scale (4.1 Gt in 2018 - USGS) so its production contributes over 5\% of anthropogenic $\mathrm{CO}_{2}$. Indirect emissions from burning fossil fuels to heat the kiln can be reduced by burning alternative fuels, including natural gas, biomass and waste-derived fuels such as tyres, sewage sludge and municipal solid wastes. These less carbon-intensive fuels might reduce overall carbon emissions by 18-24 percent from 2006 levels by 2050 but efficiency gains in cement production are incremental and yield diminishing returns.

Practically, the greatest saving is to be made through reducing the amount of cement clinker used in concrete production. Numerous supplementary cementitious materials (SCMs) exist and some have been in use for many years, whilst new materials are developed regularly (Scrivener 2017) Through the use of blended cements we have a range of Portland-SCM binders, some of which offer strength or durability advantages over Portland cement concrete. Focus in recent years has turned to non-Portland cement binders, such as Magnesia Cements, Celitement, Alinite Cement, Calcium sulphoaluminate systems, and Alkali Activated Systems / Geopolymers and each has a role to play in the future of construction. The practicality of such alternatives must be assessed at many levels; the fiscal and environmental impact must be balanced against the long-term security of supply and performance of the materials in service. The environmental case is summarized in a recent Chatham House report . A detailed understanding of the materials chemistry of these systems allows informed decision making throughout the expected service life. In addition to modelling the energetics and chemistry of cement and concrete production, modelling their behaviour in service, allows an increased understanding of the chemical constraints on durability and the maximizing of practical service life.

\section{Modelling}

The preceding text outlines the drivers for model development and it is important next, to consider developments in the fundamental discipline. Prior to widespread computer use, modelling was a relatively modest activity, applying equations which relate compositional data and perhaps the most widely known example is the Bogue equation of 1929. Bogue related the major oxides of Portland cement $\left(\mathrm{CaO}, \mathrm{SiO}_{2}, \mathrm{Al}_{2} \mathrm{O}_{3}, \mathrm{Fe}_{2} \mathrm{O}_{3}, \mathrm{SO}_{3} \mathrm{~K}_{2} \mathrm{O}\right.$ and $\left.\mathrm{Na}_{2} \mathrm{O}\right)$ through a 
direct, mass-balance calculation to the four dominant clinker minerals in the system $\left(\mathrm{C}_{2} \mathrm{~S}, \mathrm{C}_{3} \mathrm{~S}\right.$, $\mathrm{C}_{3} \mathrm{~A}$ and $\mathrm{C}_{4} \mathrm{AF}-$ where $\mathrm{C}=\mathrm{CaO}, \mathrm{S}=\mathrm{SiO}_{2}$, etc.). Whilst the approach has obvious appeal, it disregards solid solutions and consequently underestimates $\mathrm{C}_{3} \mathrm{~S}$. Over the subsequent 90 years, this simple model has been widely adopted, despite its limitations (Gutteridge 1984, Stutzman, 2008) has been modified and enhanced (Taylor 1989) and remains in use today.

\section{High Temperature Thermodynamics}

Extending this approach to consider the evolution of the bulk composition of the raw meal to the phase assemblage of the final clinker, requires more a sophisticated approach than that above and numerous authors have reported work with a range of codes and data used to predict high temperature reactions of cements. Space precludes discussion of the earliest work, yet certain landmark papers illustrate recent developments and key limitations. Damidot et at. (2014) present a comprehensive review of the field and document important early works.

The phase assemblage of Portland cement clinker was examined by Barry and Glasser who used MTDATA and the NPL/MIRO Oxide data 'MTOX' to simulate reactions in the CaO$\mathrm{SiO}_{2}-\mathrm{Al}_{2} \mathrm{O}_{3}-\mathrm{Fe}_{2} \mathrm{O}_{3}$ system, cooling from $1450^{\circ} \mathrm{C}$ to solidification. This work predicted the phase relationships in the clinker at specific temperatures and followed the reaction path during solidification, considering the effect of latent heat on reaction kinetics. They initially simulated each reaction step at thermodynamic equilibrium and compared this with Sheil cooling. This is a disequilibrium approach which applies equilibrium calculations with some constraints, such that once a component has partitioned from the liquid to the solid phase, it is prevented from undergoing further reaction. This is an important method in studies of solidification and applies the Scheil-Gulliver equation (Gulliver 1942, Scheil 1913) and four key assumptions: (i) No diffusion occurs in solid phases once they are formed (ii) Infinitely fast diffusion occurs in the liquid at all temperatures by virtue of a high diffusion coefficient, thermal convection, Marangoni convection, etc. (iii) Equilibrium exists at the solid-liquid interface, and so (iv) Compositions from the phase diagram are valid. The study made direct comparison between the two models and the Bogue calculation and the authors concluded that the Scheil approach is the most realistic.

Table 1. The fractional amounts of phases calculated to form as a result of Scheil cooling of a clinker $\left(\mathrm{CaO} 69, \mathrm{Fe} 2 \mathrm{O} 33.6, \mathrm{Al}_{2} \mathrm{O}_{3} 5.4, \mathrm{SiO}_{2} 22\right)$ from $1450^{\circ} \mathrm{C}$ to $1280^{\circ} \mathrm{C}$ compared with those calculated for equilibration at $1327^{\circ} \mathrm{C}$ and with the Bogue calculation. After Barry and Glasser (2000).

\begin{tabular}{|l|l|l|l|l|l|l|}
\hline Phase & $\mathrm{C}_{3} \mathrm{~S}$ & $\mathrm{C}_{2} \mathrm{~S}$ & $\mathrm{C}_{3} \mathrm{~A}$ & Ferrite & $\mathrm{CA}$ & $\mathrm{C}_{12} \mathrm{~A}_{7}$ \\
\hline Equilibrium cooled & 0.7206 & 0.0871 & 0.0867 & 0.1056 & 0.003 & 0.0087 \\
\hline Scheil cooled & 0.7558 & 0.0606 & 0.0482 & 0.1266 & 0.003 & 0.0087 \\
\hline Bogue calculation & 0.7105 & 0.0945 & 0.0854 & 0.1096 & 0.003 & 0.0087 \\
\hline
\end{tabular}

A similar approach was used by Ghanbari Ahari et al. (2004) who extended the system to include $\mathrm{MgO}, \mathrm{K}_{2} \mathrm{O}$ and $\mathrm{Na}_{2} \mathrm{O}$ over a wider temperatuire range: 700 to $1700^{\circ} \mathrm{C}$. They compared two codes: MTDATA and FactSage which employed different thermodynamic databases. Although the findings are very similar between the two codes (i.e. the numerical model) and to 
the work of Barry and Glasser, this paper illustrates the importance of on the choice of stoichiometric or solution compounds (the conceptual model) and of critically assessed and internally consistent data.

Recent work by Hökfors et al. (2015) follows a similar approach using FactSage but on a more complex system chemistry. The major elements considered were $\mathrm{Ca}, \mathrm{Si}, \mathrm{Al}, \mathrm{Fe}$ and $\mathrm{Mg}$, along with minor components $\mathrm{K}, \mathrm{Na}, \mathrm{S}, \mathrm{P}, \mathrm{Cl}, \mathrm{Zn}$ and $\mathrm{Ti}$, and gas-phase reactions were considered including $\mathrm{O}, \mathrm{C}, \mathrm{H}$ and $\mathrm{N}$ present both in the solid oxides and kiln atmosphere. These researchers gave particular attention to the subsolidus reactions in the ternary sub-system silicon dioxidecalcium oxide-phosphorus pentoxide $\left(\mathrm{SiO}_{2}-\mathrm{CaO}-\mathrm{P}_{2} \mathrm{O}_{5}\right)$. The calculations explain clearly the role of phosphorus in stabilizing belite in the clinker. Figure 1 compares the equilibrium-cooled predictions with those invoking Sheil cooling:
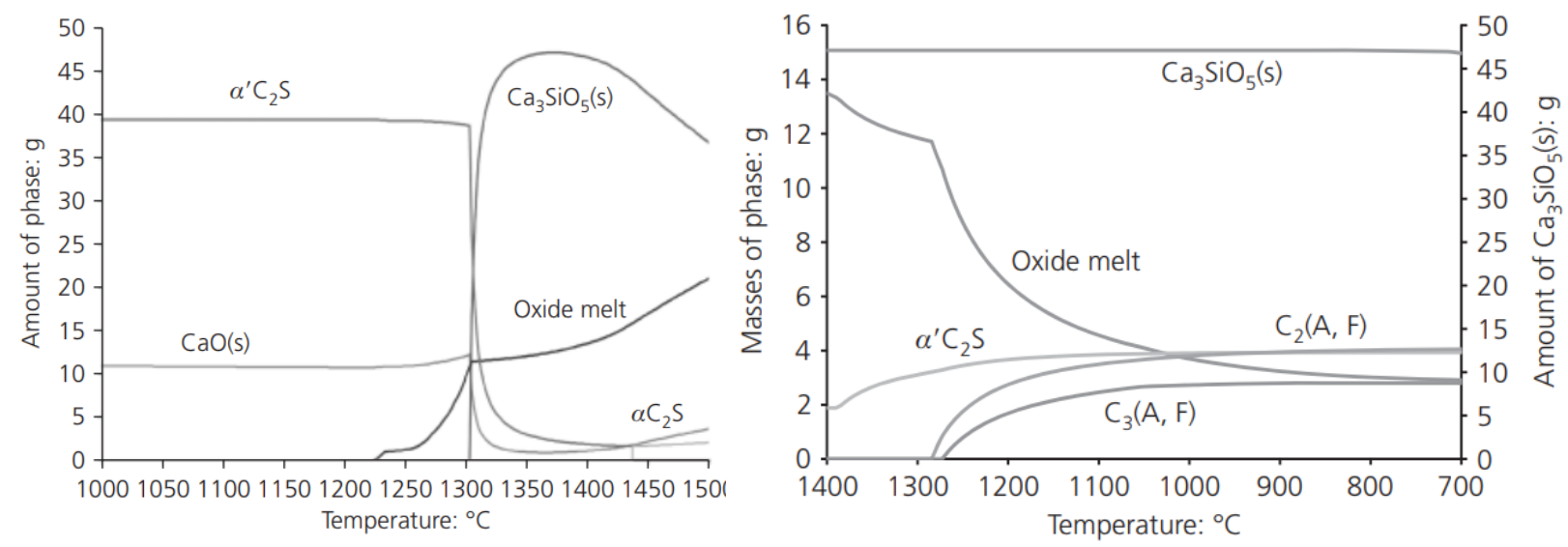

Figure 1. Left: Mass of each major phase in chemical equilibrium as a function of temperature Right: Scheil cooling of cement clinker (only major phases are included); cooling rate was $10^{\circ} \mathrm{C}$ per calculation step. After Hökfors et al. (2015)

The interactions between the solid, liquid and gas phases at high temperature are illustrated well in a suite of related papers exploring ternesite and ye'elemite stability. Hanein et al. (2017) report the synthesis of ternesite $\mathrm{Ca}_{5}\left(\mathrm{SiO}_{4}\right) 2 \mathrm{SO}_{4}$ its characterisation and their derivation of the thermodynamic properties used in the simulations.

The thermodynamic stability of ternesite was calculated as a function of temperature and $\mathrm{SO}_{2}$ partial pressures as shown in Figure 2 where the oxygen partial pressures are fixed at $21 \% \mathrm{v} / \mathrm{v}$ (similar to air) and $2 \% \mathrm{v} / \mathrm{v}$ (similar to that in a conventional cement kiln) respectively. These calculations were established by assuming that the volume of gases is much larger than that of the solids (i.e., $\mathrm{SO}_{2}$ and $\mathrm{O}_{2}$ are available in excess. 

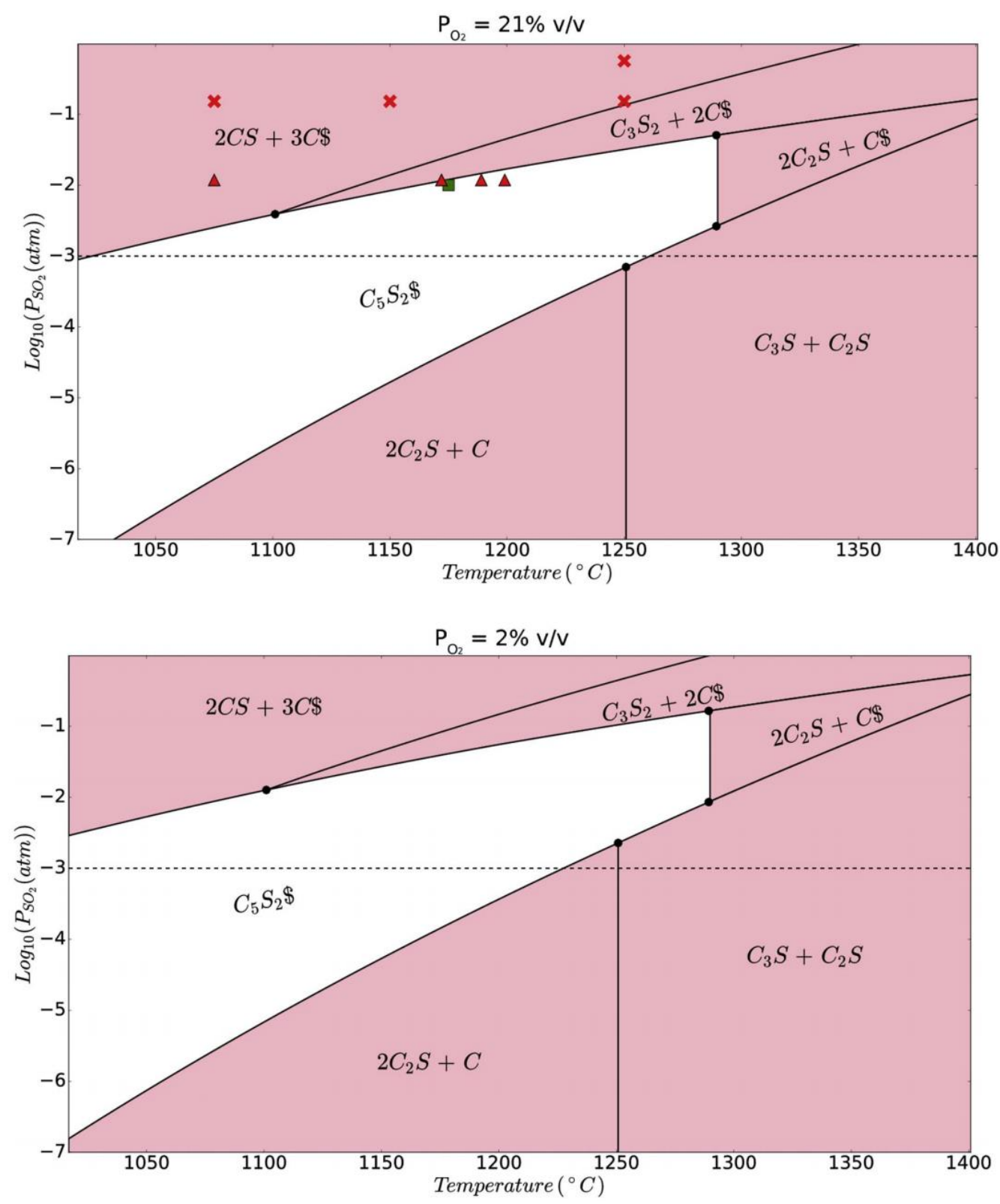

Figure 2. Ternesite stability as a function of temperature and $\mathrm{SO}_{2}$ partial pressures at constant oxygen partial pressure of $21 \% \mathrm{v} / \mathrm{v}$ (atmospheric conditions, above) and $2 \% \mathrm{v} / \mathrm{v}$ (kiln conditions, below) Ternesite is stable in the clear area. Triangles indicate where ternesite was formed in the experiments, whilst crosses mark where it did not. After Hanein et al. (2017).

The authors note "It is uncommon in cement chemistry to find phases whose stability is influenced by the fugacity of gaseous species within the normal temperature range of the clinkering process but calcite, ye'elimite, anhydrite, spurrite, and ternesite are notable exceptions along with the well-known alkali sulfate vapour/gas/solid cycle. In our thermodynamic calculations, ternesite is found to have an upper limit stability temperature of $\approx 1290{ }^{\circ} \mathrm{C}$ above which, ternesite will decompose at 1 atm pressure regardless of the atmospheric conditions; this is in agreement with the literature. However, this temperature is not fixed: it is a conditional upper limit dependent on the gas fugacity".

This is an elegant use of thermodynamic modelling to delineate the pressure-temperatechemistry conditions under which a cement mineral is likely to be stable. 


\section{Limitations and Future Trends}

In concluding this discussion, it may be useful to consider the current limitations on high temperature modelling and to speculate where the next developments will lie. Certainly, one limitation is in the lack of a widely accepted, critically assessed and internally consistent database for high temperature phases in cements. Many researchers working in the field maintain (and often share) their in-house data, refining it as new determinations are made and reporting it through publication. In parallel there are several commercial databases available for use with specific codes, a number of which are of extremely high quality, yet are not publically available. The reason for this is quite simple: some are the product of many years work and have been sponsored by a large number of investors who naturally, wish to maintain their technical lead over commercial competitors. Although the data are published and referenced, the database as a product is only available to its subscribers. The quality control of such products is generally very high, their producers adhering to strict CALPHAD methods and contributing to the international group on thermochemistry, SGTE. The history of one long-running project in oxide data (including cements) is reported by Gisby et al. (2017). In the field of low temperature thermodynamics, there have been numerous international projects intended to harmonise and assess thermochemical data for use in environmental protection, especially in geochemistry for nuclear waste studies. The EU CHEMVAL programme is one example, which united national regulatory agencies with nuclear operators and the obvious driver of public safety gave momentum to such widespread collaboration. One consequence of this was the need to examine the near field chemistry of waste repositories and this gave the initial impetus to cement chemistry modelling and database development. As yet, there is not the same drive to provide a similar vehicle for collaboration in high temperature modelling, although the climate change agenda may add some force in the future.

Looking forward, there is a very pleasing trend in materials modelling, where co-operation and exchange of ideas between disciplines is increasingly common. Only a decade ago, there was little interaction between thermodynamic modellers and workers in quantum mechanical methods, yet latterly, the two are developing synergistically. The prediction of thermodynamic properties from atomistic simulation though not widespread, is gaining momentum. A recent example by Pisch and Pasturel (2019) uses density functional theory to predict the heat of formation of ye'elemite. Atomistic simulation using DFT methods is more widely applied in structural chemistry and Tao et.al (2019) have used the approach successfully to examine zinc partitioning between clinker minerals in the cement kiln.

Phase field methods bridge the world of structural modelling and chemical kinetics and the approach is attracting the attention of the cements research community. In essence, the method concerns the prediction of boundary evolution between spatial domains and an example relevant to cement science would be melillite-merwinite dendrite formation in slag glasses. Work by Heuens et al.(2011) is tantalisingly close to the system chemistry of cements and it seems inevitable that the methods will be applied to cementitious materials in the very near future. For an introduction to the field, Provatas and Elder have made their book available on the McGill server and Moelans et al (2008) gives a thorough overview. 
Finally, it probably does not need to be said, that the future of high temperature thermodynamics is likely to evolve quickly, with contributions from related fields in structural modelling, chemical kinetics and from coupled methods, such as chemical-transport and heatflow models. It is almost inevitable that the research community will adopt a common thermodynamic database, probably through the offices of an existing consortium (SGTE? NIST? MIST?) or some consortium thereof. The interest of the cement producers is strong and the drivers are well-defined. High temperature thermodynamics has a bright future.

\section{REFERENCES}

Alexander Pisch Alain Pasturel On the heat of formation of ye'elimite $\mathrm{Ca}_{4} \mathrm{Al}_{6} \mathrm{O}_{12} \cdot \mathrm{SO}_{4}$ using density functional theory Advances in Cement Research Volume 31 Issue 3, March, 2019, pp. 106-112

B Hökfors, D Boström, E Viggh and R Backman (2015) On the phase chemistry of Portland cement clinker Advances in Cement Research Volume 27 Issue 1

CALPHAD (1970) L. Kaufman and H. Bernstein: Computer Calculations of Phase Diagrams, Academic, New York, 1970. N. Saunders, A.P. Midownik CALPHAD, A Comprehensive Guide, Elsevier (1998)

Chatham House Report. Johanna Lehne and Felix Preston. Energy, Environment and Resources Department. June 2018 Making Concrete Change. Innovation in Low-carbon Cement and Concrete

CHEMVAL Read., D. \& Falck., W.E (1996) (editors) “CHEMVAL-2 A Co-ordinated research initiative for evaluating and enhancing chemical models in radiological risk assessment” CEC Publ. EUR-16648EN. Environment Agency (1996)

C.W.Bale E.Bélisle P.Chartrand S.A.Decterov G.Eriksson A.E.Gheribi K.Hack I.-H.Jung J.Melançon A.D.Pelton S.Petersen C.Robelin J.Sangster P.Spencer M-A.Van Ende FactSage thermochemical software and databases, 2010-2016 CalphadVolume 54, September 2016, Pages 35-53

Damidot, D. ; Lothenbach, B. ; Herfort, D. ; Glasser, F.P. Thermodynamics and cement science Cement and Concrete Research, 2011, Vol.41(7), pp.679-695

Guttridge W A. Quantitative x-ray powder diffraction in the study of some cementive minerals. British Ceramic Society Proceedings, 1984,35, 11-35. 
Gulliver, G.H., J. Inst. Met., 9:120, 1913.

H. F. W. Taylor Modification of the Bogue calculation. Advances in Cement Research. Volume 2 Issue 6, April 1989, pp. 73-77

J. Heulens B. Blanpain, N. Moelans A phase field model for isothermal crystallization of oxide melts Acta Materialia Volume 59, Issue 5, March 2011, Pages 2156-2165

Karen L. SCRIVENER, Vanderley M. JOHN and Ellis M. GARTNER (2018) Eco-efficient cements: Potential economically viable solutions for a low- $\mathrm{CO}_{2}$ cement based materials industry United Nations Environment Program Report

K. Ghanbari Ahari, D. Thompson, B.B. Argent, J.H. Sharp "Phase Equilibria Predictions by Computational Calculations on Portland Cement Clinker ", Key Engineering Materials, Vols. 264-268, pp. 2131-2136, 2004

MTDATA and MTOX (2002) R.H. Davies, A.T. Dinsdale, J.A. Gisby, J.A.J. Robinson, and S.M. Martin: Calphad, 2002, vol. 26, pp. 229-71.

MTDATA and the Prediction of Phase Equilibria in Oxide Systems: 30 Years of Industrial Collaboration. Gisby, John ; Taskinen, Pekka ; Pihlasalo, Jouni ; Li, Zushu ; Tyrer, Mark ;

Moelans, Nele ; Blanpain, Bart ; Wollants, Patrick An introduction to phase-field modeling of microstructure evolution Calphad, 2008, Vol.32(2), pp.268-294

Nikolas Provatas and Ken Elder Phase field methods in materials science and engineering. Wiley VCH http://www.physics.mcgill.ca/ provatas/papers/Phase_Field_Methods_text.pdf

Paul Stutzman Alan Heckert Amelia Tebbe Stefan Leigh. Uncertainty in Bogue-calculated phase composition of hydraulic cements. Cement and Concrete Research Volumes 61-62, July-August 2014, Pages 40-48

Pearce, Jonathan ; Avarmaa, Katri ; Björklund, Peter ; Davies, Hugh ; Korpi, Mikko ; Martin, Susan ; Pesonen, Lauri ; Robinson, Jim. Metallurgical and Materials Transactions, Feb 2017, Vol.48(1), pp.91-98

Isabel Galan, Ammar Elhoweris, Theodore Hanein, Marcus N. Bannerman, Fredrik P. Glasser (2017), 'Advances in Clinkering Technology of Calcium Sulfoaluminate Cement'. 29(10), pp. 405-417 ACR Volume 29, Issue 10, November, 2017

R.H. Bogue. Calculation of the compounds in portland cement. Industrial and Engineering Chemistry, 1(2):192-197, 1929. 
Scheil, E., Z. Metallk., 34:70, 1942.

Stability of ternesite and the production at scale of ternesite-based clinkers Theodore Haneina,*, Isabel Galanb , Fredrik P. Glasserb , Solon Skalamprinosb , Ammar Elhowerisb , Mohammed S. Imbabia, Marcus N. Bannermana,* Cement and Concrete Research Volume 98, 2017, p 91-100

SGTE https://www.sgte.net

USGS (Annual publication) Cement Statistics and Information. United states Geological urvey Mineral Commodity reports 1996 - 2019

Yong Tao Neng Li Wenqin Zhang Fazhou Wang Shuguang Hu. Understanding the zinc incorporation into silicate clinker during waste co-disposal of cement kiln: A density functional theory study Journal of Cleaner Production May 2019 In Press, Accepted Manuscript 